\section{Sex Reversal in Copepods}

BeTwEen February and June 1947, 20.5 per cent of the males, 3.7 per cent of the females and $0 \cdot 3$ per cent of the copepodids of Pseudocalanus elongatus Boeck, collected from six stations between Flamborough Head and the Dogger Bank, were found to be parasitized by Blastodinium contortum hyalinum Chatton. Almost all the observed parasites were found to be in the tetrablastic or a later stage, with a length of 440-560 $\mu$. They occurred singly in the vast majority of cases, but very rarely two individuals were found in the same Pseudocalanus. As the material was unstained, it is likely that most of the earlier stages of the parasite were overlooked, particularly in the younger stages of the copepodids, and that the proportion of infected individuals was really higher than that given.

Chatton ${ }^{1}$ states that the presence of Blastodinium causes the castration of the host without, however, this affecting its external structure; on the other hand, it brings about a comparative reduction in its maximum size. $\mathrm{H}_{\Theta}$ did not find any parasitized adult males, and thought that the parasite arrested the development of the last copepodid by inhibiting the final moult. Chatton recorded infection of Pseudocalanus sp. from the North Sea.

In the parasitized material dealt with here, while the stage V male and female copepodids and the mature females had normal external features, there were present abnormal individuals. Some of these showed a full development of the female abdomen, vulva and all other characters such as antennæ, but with the presence of a fifth pair of legs. The legs were in a state of development corresponding with that in one of the male copepodid stages. Contrary to Chatton, I have found these infected copepods to be, if anything, slightly larger than the comparable non-parasitized individuals. I have recorded to date three individuals in this category which had an attached spermatophore (Fig. 1).

I have found also several infected individuals such as that shown in Fig. 2, in which the female type of

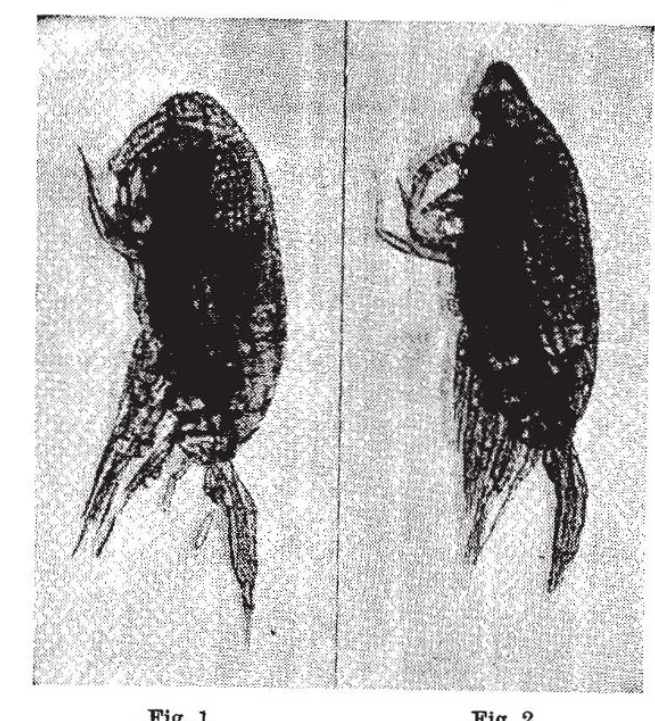

Pseudocalanus elongatus BOECK FROM THE SOUTHERN NORTH SEA, PARASITIZED BY Blastodinium contortum hyalinum CHATTON. PHOTOMIOROGRAPHS OF TWO UNTREATED AND UNMOUNTED INDIVIDUALS PRESERVED IN FORMALIN. LENGTH OF CEPHALOCHORAX : FIG. $1,950 \mu$; FIG. $2,920 \mu$. MAG. $\times 40$ abdomen is not fully formed, showing the presence of the vulva, but with the abdominal segments 1 and 2 not completely fused together. The proportions of the remaining segments are typical of the male sex. These individuals possess, moreover, a pair of fully formed male fifth legs. The contained parasite measures about $310 \mu$ in length and is in either the di- or triblastic stage.

These observations suggest that the parasite exercises no effect on the morphology of the female sex of the host, and that the last copepodid stage passes on to the fully formed but castrated individual. In the male sex, however, the parasite at some stage in its growth is able to arrest the development of the male characters of the copepodid (externally the fifth pair of legs), while in the final ecdysis it causes the copepod to undergo sex reversal and become a superficially mature but sterile female. The presence of the fifth pair of legs remaining in a state of develop. ment comparable to that in the animal's previous stage is the only indication of the original male sex.

It appears most likely that the individual of Fig. 2 became parasitized first at a later stage in its development than usual, and that it was able to reach the fully mature male stage before the parasite could exercise control over its morphology. Whether the individual could show the complete external sex change described when the parasite approaches its maximum size remains to be seen.

It is apparent that the abnormal 'females', under the influence of the parasite, have undergone com. plete sex reversal, for it has been shown that males find them as attractive as normal females and effect copulation (vide Fig. 1). The sex reversal is, however, virtual, not absolute, as according to Chatton the copepods are castrated.

Although the incidence of infection has been shown to be considerable, the castration which occurred does not seem to have caused any substantial drop in the population of Pseudocalanus, as large numbers of uninfected juvenile forms were found in June at the end of the period.

I am indebted to Colonel Seymour Sewell for suggesting the possible identity of my parasite and also for referring me to Chatton's paper.

Fisheries Laboratory,

\section{J. G. Catthey} Lowestoft. Feb. 23.

${ }^{1}$ Chatton, E., Arch. Zool. exp. gen., 59, 1, pls. I-XVIII (1920).

\section{Evaluation of Herbage for Grazing}

IN the numerous published accounts of digestibility trials with cut herbage, the assumption has been made $^{1}$ that the herbage fed represents that which grazing animals would eat. It is known, however, that animals select grass and clover leaf in preference to stem when grazing ${ }^{2,3}$; these are the more nutritious constituents of the sward, so that by feeding the whole cut from the sward, the nutritive value of the portion stock would eat in the field is under. estimated. Thus we need to measure the feeding value of a portion of the sward that we cannot actually analyse, namely, that taken off by the grazing animal. This problem is being investigated at the Grassland Improvement Station. 